\title{
Artivismo musical e feminismos: arte e política nas disputas visuais e no direito de existir das dissidências sexuais e de gêneros
}

\author{
Musical artivism and feminisms: art and politics in the visual disputes and \\ concerning the right to exist of the sexual and gender dissidence
}

\author{
Artvismo musical y feminismos: arte y política en las disputas visuales y \\ relacionadas con el derecho de existir de las disensiones sexuales y de \\ géneros
}

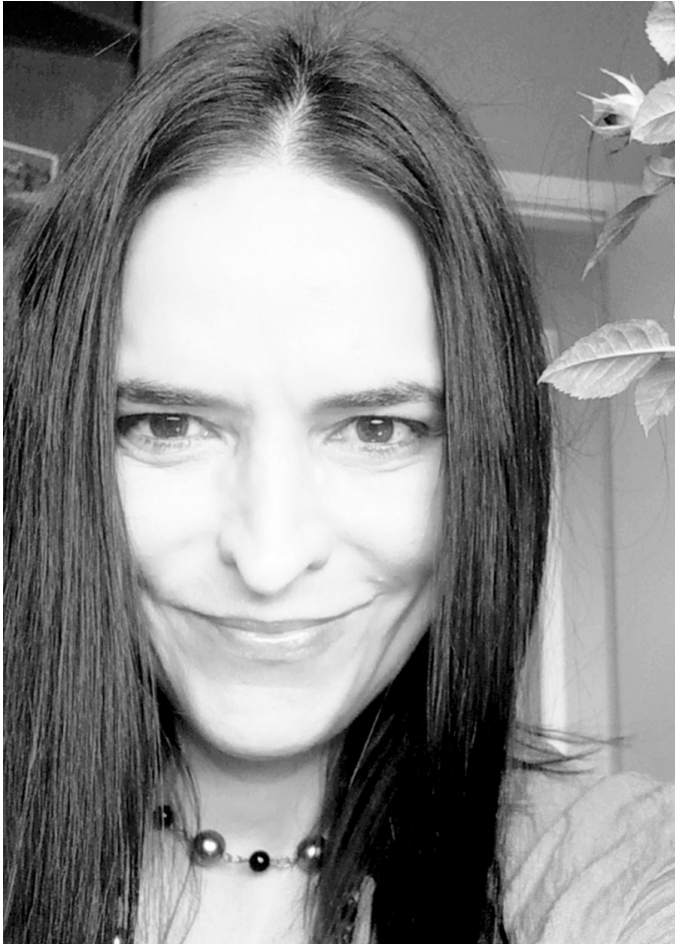

Em entrevista à Reciis, a cientista Rose de Melo Rocha compreende seus estudos baseados em um conhecimento encarnado que se espraia por suas atuações como pesquisadora, professora e cidadã. Em sua trajetória intelectual, procura pensar a comunicação como um processo de vinculação com implicações afetuais e subjetivas em temas como culturas urbanas, juvenis e audiovisualidades. Tais temáticas se entrecruzam e se reencontram nos seus estudos recentes sobre corporalidades e dissidências sexuais e de gênero. Rose de Melo Rocha observa o entretenimento e, particularmente, o que denomina de artivismo musical de gênero como um campo de ruptura em relação à arte e a um posicionamento ativista que problematiza a política institucional. As cantoras Pabllo Vittar e Linn da Quebrada são pensadas como entradas protagônicas e dissidentes nas disputas audiovisuais, construindo outras audiovisualidades como projeções de utopias realizáveis. O que importa para a pesquisadora, e para os grupos nos quais se aliança, é ir além do discurso da resistência a fim de fortalecer o direito de existir, o direito à presença. Nesse sentido, defende um feminismo que não se restrinja a um essencialismo identitário. Rose de Melo Rocha é professora titular e pesquisadora do Programa de Pós-Graduação em Comunicação e Práticas de Consumo da Escola Superior de Propaganda e Marketing de São Paulo (ESPM/SP).

Palavras-chave: Artivismo; Feminismo; Gêneros; Sexualidade; Comunicação. 
In an interview given to Reciis (Revista Eletrônica de Comunicação, Informação \& Inovação em Saúde Electronic Journal of Communication, Information \& Innovation in Health), Fiocruz, Brazil, the scientist Rose de Melo Rocha reveals how her studies are based on an embodied knowledge that spreads over her acting as reseacher, professor and citizen. In her intellectual trajectory, she searches for a thinking on communication as a bonding process that has 'affective' and subjective implications for themes such as urban and youthful cultures, and audiovisuals. Such thematic approaches intersect as well come together in her recent studies about corporality and sexual and gender dissidence. Rose de Melo Rocha observes the entertainment and particularly what she calls the 'gender musical artivism' and she see them as a field of rupture regarding the art and an activist posture that poses under discussion the institutional politics. The singers Pabllo Vittar and Linn da Quebrada are seen as emblematic protagonists and dissidents in audiovisual disputes, building others audiovisuals as projections of attainable utopias. What is important to the researcher and to groups with she has alliances is go beyond the discourse of resistance so that to strengthen the right to exist, the right to the presence. In this sense, she advocates a feminism that is not restricted to an identity essentialism. Rose de Melo Rocha is a professor and reseacher in the Programa de Pós-Graduação em Comunicação e Práticas de Consumo at Escola Superior de Propaganda e Marketing de São Paulo (ESPM/SP), Brazil.

Keywords: Artivism; Feminisms; Genders; Sexuality; Communication.

En una entrevista concedida a Reciis (Revista Eletrônica de Comunicação, Informação \& Inovação em Saúde - Revista Electrónica de Comunicación, Información \& Innovación en Salud), Fiocruz, Brasil, la científica Rose de Melo Rocha revela cómo sus estudios se basan en un conocimiento encarnado que se extiende en sus actuaciones como investigadora, profesora universitaria y ciudadana. En su trayectoria intelectual busca pensar en la comunicación como un proceso de vinculación que tiene implicaciones 'afectivas' y subjetivas para temas como las culturas urbanas y juvenis y los audiovisuales. Estos enfoques temáticos se entrecruzan y se reencuentran en sus recientes estudios sobre corporalidad y disensiones sexuales y de género. Rose de Melo Rocha observa el entretenimiento y, en particular, el que ella denomina 'artvismo musical de género' y los ve como un campo de ruptura con respecto al arte y un posicionamiento activista que problematiza la política institucional. Las cantoras Pabllo Vittar and Linn da Quebrada son vistas como protagonistas y disidentes emblemáticas en disputas audiovisuales, construyendo otros audiovisuales como proyección de utopias realizables. El que es de importancia para la investigadora y para los grupos con los cuales ella tiene alianza es ir más allá del discurso de resistencia para que se fortalezca el derecho de existir, el derecho a la presencia. En este sentido, ella aboga por un feminismo que no se limite al esencialismo identitario. Rose de Melo Rocha es profesora universitaria y investigadora en el Programa de Pós-Graduação em Comunicação e Práticas de Consumo de la Escola Superior de Propaganda e Marketing de São Paulo (ESPM/SP), Brasil.

Palabras clave: Artivismo; Feminismo; Géneros; Sexualidad; Comunicación. 


\section{Reciis: Como compreende sua trajetória acadêmica no campo da comunicação e particularmente nos estudos de gêneros e sexualidades?}

Rose de Melo Rocha: Minha trajetória é relativamente plural, mas com núcleos condutores bastante evidentes. Compreendo-a naquela direção proposta pelo escritor argentino Jorge Luís Borges: são veredas que se bifurcam (BORGES, 2007). É assim que a percebo. Sempre tive um interesse muito forte por epistemologia e por filosofia da comunicação e, ao mesmo tempo, por aquilo que entendo como epistemes e pedagogias libertárias. Mobilizam-me aqueles objetos de pesquisa que autores como Omar Rincón (2015) chama de objetos bastardos e eu de objetos borrosos, ruidosos. Esses acontecimentos me encantam. Nessa direção, construí uma trajetória de pesquisa na proximidade com o estudo das culturas urbanas, das culturas juvenis e das audiovisualidades.

Existe também uma recorrência que reside na compreensão da centralidade dos processos comunicacionais para se analisar tais dinâmicas. Considero que os processos comunicacionais têm uma dimensão social estruturante, mas, na minha perspectiva, eles também devem ser lidos para além dos midiacentrismos e da mera reprodução. Ou seja, nesse sentido sou barberiana (MARTÍN-BARBERO, 2004, 2010), e aqui presto uma homenagem ao nosso querido mestre que nos deixou há pouco. Como MartínBarbero, analiso a comunicação como produção, como processo. Minha biblioteca retrata esta trajetória plural, com suas muitas convergências. Fiz o exercício de observá-la antes de conceder esta entrevista. Essa biblioteca contém uma grande bibliografia sobre cidades, sobre imagens e audiovisualidades, sobre tecnologia, sobre juventudes, sobre corpo. Nos últimos anos, ganhou um volume muito grande sobre estudos de gênero, mas também sobre estética e filosofia. E há uma parte enorme dessa biblioteca vinculada a metodologia e epistemologia.

Entendo que minha formação como pesquisadora começa na graduação em Comunicação Social, habilitação em jornalismo, na Universidade Federal de Minas Gerais (UFMG). Sou filha da universidade pública e dos estágios universitários. Fui uma jovem estudante que estagiou no Jornal Laboratório, mas também junto ao Núcleo de Pesquisa e, posteriormente, no Núcleo de Estudos Audiovisuais. No meu primeiro ano de universidade, participei como estagiária de uma pesquisa que me marcou bastante e visava a uma reformulação curricular que enfrentava a separação entre teoria e prática. Tive a sorte de ser supervisionada nesse início pela professora Vera Veiga França, que de alguma forma foi também a mentora da realização do meu mestrado no Instituto Metodista de Ensino Superior, em São Bernardo do Campo/SP. Sempre soube que seria pesquisadora, mas jamais concebi a pesquisa como algo separado da prática. Ao falar isso, já respondo também algumas das razões que me levam aos estudos de gênero. Pratico uma pesquisa encarnada. Sou uma pesquisadora implicada, que opta por metodologias 'processuais' e 'multisituadas'. Essa perspectiva está na base do meu permanente interesse na relação entre estética e política, o que me permitiu desde o início pensar a comunicação como um processo de vinculação com implicações afetuais e subjetivas.

Tomando por inspiração o que Stuart Hall propõe sobre o conceito de identidade (HALL, 2004), creio que o conceito de academia deva ser colocado sob rasura, e, nessa direção, nos voltemos às nossas trajetórias intelectuais e como intelectuais, e não apenas como acadêmicas e acadêmicos. Cada vez mais, estamos sendo convocados a nos apresentar como intelectuais. Fazemos parte deste mundo, estamos imersos no mundo, não estamos à parte dele. Nessa direção, existe uma sinergia total entre minha vida de professora, de pesquisadora, de intelectual, e minha vida como cidadã. Iniciei minha militância política muito jovem, aos 13 anos, de início em movimentos ambientalistas, passando pelo movimento estudantil e, posteriormente, participei de um grupo feminista que atuava na cidade de Belo Horizonte (MG), de onde eu vim. É interessante que, de algum modo, eu me reencontro hoje de maneira significativa com essa trajetória. 
Reciis - Revista Eletrônica de Comunicação, Informação \& Inovação em Saúde, Rio de Janeiro, v. 15, n. 1, p. 476-488, jan./mar. 2021 [www.reciis.icict.fiocruz.br] e-ISSN 1981-6278

Reciis: Poderia comentar sobre suas pesquisas desenvolvidas no mestrado e doutorado que dizem respeito a comunicação, estéticas e cidades - como, por exemplo, manifestações 'grafitadas' no espaço-tempo urbano e estéticas da violência?

Rose de Melo Rocha: Quando vim para a cidade de São Paulo (SP), estudaria cinema documental, mas descobri que o Programa de Pós-Graduação a que me vincularia não se dedicava a essa vertente de estudos. Elaborei então um novo projeto de pesquisa que se articulava a minha herança de militância estudantil, sobre relações de trabalho nas redações dos jornais. Mas ele também não pôde ir adiante. Então, um dia, saindo da Metodista, onde estudava, e pensando que tema, no final das contas, iria investigar, sou surpreendida por um acontecimento comunicacional potente. Com meu corpo imerso no corpo da cidade, emergiu com clareza aquele que seria o tema de meu mestrado: os grafites e as pichações na cidade de São Paulo (ROCHA, 1992). Esse projeto de mestrado foi construído na interface da pesquisa teórica profunda e da pesquisa de campo, fundamental para que eu tivesse acesso aos grupos de grafiteiros e grafiteiras. Travei um contato bastante intenso com eles. Aprendi a grafitar, sem intenção de me tornar grafiteira. E ali já começo a perceber a questão de gênero pela relação com as jovens grafiteiras, 'as minas' que viviam na cidade. Fica evidente para mim como uma ação política e institucional faz diferença na relação com essas juventudes em suas generificações. Durante o processo desse mestrado, Luiza Erundina era quem conduzia a Prefeitura e ela também vai a campo e ao encontro desses jovens. Pela primeira vez, as meninas, as grafiteiras muito jovens, disseram que ao serem acolhidas por uma mulher, no caso a Erundina, não se sentiram ameaçadas.

Ao fim do mestrado, travei contato mais intenso com grupos de pichadores. Ali percebo qual seria o meu novo tema de pesquisa: a estética da violência (ROCHA, 1998). Porque esses jovens pichadores, em sua maioria meninos periféricos, muitos deles negros, mostraram para mim como muitas vezes a linguagem da violência estetizada é um recurso de sobrevivência psíquica e existencial. Tracei meu tema de doutorado a partir desse encontro com esses jovens pichadores. Terminei o doutorado muito impactada com tudo que vi, li, ouvi e vivi. Fiz meu primeiro pós-doutorado na Pontifícia Universidade Católica de São Paulo (PUC-SP), em Ciências Sociais e Antropologia. Depois de meses assistindo aos primórdios da carreira de apresentadores como Ratinho, tendo assistido e transcrito horas e horas de telejornais sensacionalistas, tendo estudado de perto a midiatização dos linchamentos, tendo estudado de perto o Massacre do Carandiru e outros fenômenos dessa ordem, parti para outra dimensão que era abordar as rupturas possíveis, já em andamento no Brasil, do ciclo da violência por uma via artística ou cultural. E esse foi o meu estudo de caso de pós-doutorado, do ponto de vista empírico. Há uma convergência entre essas investigações. Durante esse processo, participei de grupos de pesquisa que foram fundamentais em minha formação, como o Centro de Estudos e Pesquisas em Novas Tecnologias, Comunicação e Cultura (NTC) da Escola de Comunicação e Arte da Universidade de São Paulo (ECA-USP), dirigido pelo meu orientador de doutorado Ciro Marcondes Filho, que infelizmente nos deixou há pouco, e na PUC-SP vinculei-me ao Núcleo de Estudos da Complexidade, sob a supervisão do professor Edgard de Assis Carvalho.

Tudo isso vai me levar a compor a equipe de pesquisadoras e pesquisadores que estruturam o Projeto Jovens Urbanos, e que resultou em um livro: Jovens na cena metropolitana: percepções, narrativas e modos de comunicação (BORELLI; ROCHA; OLIVEIRA, 2009). Essa pesquisa e esse livro surgiram a partir do meu ingresso em uma rede de juvenólogos e politólogos latino-americanos. Esse ingresso aconteceu a partir de um convite do Jesus Martín-Barbero, feito à professora Silvia Borelli (PUC-SP), parceira de pesquisa e líder do projeto Jovens Urbanos, em meados de 2003. Com essa pesquisa sobre jovens urbanos - que era uma proposta de extensão internacional da investigação sobre culturas e subculturas juvenis, e concepções de vida e morte de jovens da cidade de Bogotá, na Colômbia - surge uma proposta de estender isso para 
outros países. Ali se dá minha aproximação mais efetiva com os estudos culturais latino-americanos, e, posteriormente, com a pesquisa narrativa. Na investigação sobre jovens urbanos na cidade de São Paulo, trabalhamos com duas regiões extremas da capital em termos de ocorrências de violências e de mortalidade juvenil: a Zona Oeste não periférica e a Zona Sul periférica. Nesse estudo, fiquei responsável por analisar as concepções especificamente de vida e morte relacionadas às experimentações da violência. Ali, foi revelador o marcador de gênero. Havia diferenças enormes não só nas experiências, mas nos modos de narrar as experiências vividas por meninos e por meninas. Naquele momento, em 2003, o debate de gênero era muito menos complexo do que, felizmente, hoje ele se tornou. Não havia se constituído enquanto objeto reflexivo sistemático e sistematizado para o campo da comunicação, sem a devida inclusão das variadas perspectivas, por exemplo, de gays, de lésbicas, de bissexuais, menos ainda de transsexuais e tão pouco se incluíra o debate interseccional.

Quando têm início minhas pesquisas mais propriamente autorais, esse debate e essa reflexão se consolidam como campos de estudo e de problematização. Estou me referindo às pesquisas desenvolvidas mediante bolsas de Produtividade em Pesquisa (PQ) do Conselho Nacional de Desenvolvimento Científico e Tecnológico (CNPq), de que sou beneficiária faz cerca de 10 anos, porque ali a ênfase nos debates de gênero será privilegiada. Já na primeira pesquisa, quando estudei as marchas juvenis, como a Marcha das Vadias e a Marcha da Maconha, explodiu o debate de gênero e sexualidade já em seus espraiamentos digitais, o que, para mim, reforçava o recorte nas relações estético-políticas sempre em uma dimensão pedagógica e libertária. Também sou filha de Paulo Freire (1998), ainda que uma herdeira bastarda, no sentido de Rincón (2015), que louva as contaminações. Nesse projeto de pesquisa, chamado Você marcha para quê? Sentidos do ativismo juvenil nas culturas comunicacionais e do consumo, o debate de gênero, a reformatação comunicacional da política e a emergência de novas formas de se fazer política estavam muito evidentes. E dali, realmente fui mergulhando nesse campo de estudo e assim chego ao segundo projeto PQ, Sobre (des)possessões, (des)ocupações e (in)visibilidades: lutas políticas, intervenções estéticas e ritualísticas de presença e subjetivação na relação com o corpo, a cidade, as imagens e o consumo. Aí realmente fiz muitas idas a campo, e em um desses momentos, acompanhei uma atividade presencial da Ocupação SSexBBox - que em certo sentido já não existe mais como ocupação, mas permanece como consultoria especializada em equidade social, sendo também muito potente nas ambiências audiovisuais. Então, pude acompanhar o início da Revolta da Lâmpadai, a afirmação do fervo como forma de luta, as corporalidades, as dissidências sexuais e de gênero como forças estéticas e políticas que estavam presentes de um modo bastante central. É em um dos acontecimentos presenciais da ocupação SSexBBox, na Casa da Luz, que eu encontro Rico Dalasam, multiartista, rapper, negro, gay, paulistano ${ }^{\text {ii }}$. Nesse encontro com Rico, nasce a fagulha do projeto que finalizo esse ano de 2021. Desenvolvido nos últimos três anos, esse projeto chama-se Artivismo musical de gênero em São Paulo: dinâmicas de comunicação, contextos de consumo, políticas de apresentação e audiovisibilidade em um pop encarnado e translocal. Ou seja, são caminhos que vão se entrelaçando, abrindo perspectivas, sempre muito articulados com interesses mais que temáticos. É um conhecimento encarnado que se espraia pelas minhas atuações como pesquisadora, como professora, mas também como cidadã.

i A Revolta da Lâmpada é um protesto artístico e político que acontece em São Paulo desde 2014 e alia as lutas LGBTI+, negra, feminista e de pessoas vivendo com HIV. O coletivo surgiu após o episódio de LGBT+ serem agredidos com lâmpadas fluorescentes na Avenida Paulista, em 14 de novembro de 2010, ao saírem de uma boate.

ii Jefferson Ricardo da Silva, mais conhecido como Rico Dalasam, é um cantor, compositor e rapper brasileiro. Dalasam é um acrônimo da frase 'Disponho Armas Libertárias a Sonhos Antes Mutilados'. É representante da comunidade LGBT no intitulado queer rap. 
Reciis: $O$ entretenimento é um campo bastante explorado nos seus estudos, fazendo interfaces com a temática de gêneros e sexualidades. Você elaborou um estudo que denominou de Hipermulheres as celebridades que fazem da construção do próprio corpo assemelhado à própria subjetividade, o corpo-imagem como negócio. Poderia comentar sobre esse estudo e como o entretenimento e as celebridades podem nos dizer sobre as relações comunicacionais e de gêneros?

Rose de Melo Rocha: Quando penso em entretenimento, dirijo-me mais especificamente para o universo da cultura pop e da música. Interessa-me justamente refletir sobre as potencialidades políticas do entretenimento. Gosto de relembrar uma chave de leitura, de intepretação do contemporâneo, proposta pela feminista E. Ann Kaplan (1993), que se dedicou a analisar algumas expressões da cultura pós-moderna como perspectivas para se compreender expressões e práticas de gênero. Ao analisar o pós-modernismo, ela apresenta que há um pós-modernismo utópico e um cooptado. Gosto dessa ideia para pensar que também no campo do entretenimento não temos, como tendem a construir algumas análises pouco complexas, ou uma coisa ou outra. Temos a convivência de possibilidades e impossibilidades. Elas nem sempre convergem e podem até ser conflitivas. Penso o campo do entretenimento como campo de disputa e, nesse sentido, percebo os embates sobre gêneros e sexualidades que o atravessam. Por exemplo, do ponto de vista das mulheres-fruta, o que defendi em artigo escrito há alguns anos (ROCHA, 2018) foi que nessa expressão de mulheridade existiria quase aquilo que Norval Baitello Júnior chama de iconofagia (BAITELLO, 2014). Seriam mulheres que de algum modo seriam quase que devoradas, voluntariamente, ao se assumirem como um negócio. Seriam devoradas por sua própria imagem. Inclusive pelo fato de que essa imagem modificava amplamente seus corpos.

Veja que interessante, quando olhamos para as mulheres-fruta também percebemos, por outro lado, um legado importante deixado pelas travestis. Um legado de transformação do corpo, de uma relação original entre corpo e artificialidade. E muitas vezes pode e é, hoje em dia, como os artivismos musicais de gênero trabalham de uma forma bastante potente e questionadora o enfrentamento de ordens identitárias estabelecidas ou essencialistas. Acho que dá para pensar aqui na distinção que faz Judith Butler entre performance e performatividade (BUTLER, 2003). Localizo nas mulheres-fruta uma performatividade hiperbólica de um certo feminino. Também percebo nas travestis, e em algumas existências trans, uma performance de 'outridade', que muitas vezes, como fala Preciado (2018), vai jogar de maneira contralaboratorial com todo esse input farmacopornográfico e audiovisual que nos convoca, não a gozar, mas a gozar de uma maneira supostamente correta, como se nos ensinasse a maneira correta de gozar. Butler (2003) se refere às drags com essa perspectiva de uma performance de 'outridade', como criação. Nessa direção, penso nas travestis, em sua anterioridade mesmo, no modo como trabalham as tecnologias de modificação corporal, os processos de hormonização e redesignação. Menciono as travestis para voltar ao campo do entretenimento e destacar sua relevância também na constituição de um imaginário aqui no Brasil que permitiu alguma ordem de presença e de convivência com a dissidência. Por exemplo, com a figura de Rogéria, que se nomeava 'a travesti da família brasileira', e de inúmeras daquelas que então se nomeavam transformistas. Entendo que é um espaço de tensão, de disputa e de negociação. Isso pode ser observado a partir desse universo do entretenimento. Mas há também um espaço de uniformização, de essencialização, de desqualificação e é para essa complexidade que devemos olhar com atenção. Quando se ocupa com uma intenção política, por exemplo, que se faça essa ocupação de maneira estratégica, ativa e consciente. 


\section{Reciis: Como você observa nas suas pesquisas situações e práticas de violência de gênero?}

Rose de Melo Rocha: A começar pelo meu lugar: a mulher que sou enfrenta cotidianamente violência de gênero. As pesquisas científicas não estão isentas ou alheias a essa possibilidade, sempre tomamos posição. E sempre, na tomada de posição, enfrentamos alguns dos traumas e das feridas sociais da sociedade na qual vivemos. Como mulher privilegiada que sou, na minha passabilidade como branca, sendo professora universitária, pesquisadora, de classe média, na minha cisgeneridade, na minha constituição como heterossexual, estou menos vulnerável a um sem-número de precarizações e subalternizações outras que sofrem as não pesquisadoras, as mulheres negras, periféricas, trans, travestis, lésbicas, bissexuais, panssexuais. É por essa razão, e aí chego na questão da violência de gênero enquanto objeto de investigação, a violência de gênero é tanto objeto de investigação quanto de instigação. Passei esta pandemia por uma circunstância de pesquisa e por conta de minha atuação junto ao Conselho Latino-Americano de Ciências Sociais (CLACSO), especificamente na inserção junto ao GT Infancias y Juventudes ${ }^{\mathrm{iii}}$, do qual faço parte, e por conta da pesquisa desenvolvida pela equipe Brasil, composta por um grupo de pesquisadoras e pesquisadores da PUC-SP e da Escola Superior de Propaganda e Marketing de São Paulo (ESPM-SP), imersa no contato e no tratamento de dados sobre violência de gênero, em alguns recortes: feminicídios, LGBTfobia, crimes de ódio e dados sobre a população brasileira vivendo com HIV/AIDS. O que fica evidente é que o tratamento dos dados sobre violência de gênero precisa, forçosamente, receber dois olhares: primeiro um olhar qualitativo, sem analisar os dados com esse viés não conseguimos compreender a complexidade das violências vividas e algumas estatísticas oficiais que reproduzem o corte hetero-cis-normativo-patriarcalcolonialista. Se não o fizermos, podemos reproduzir alguns desses elementos que criticamos. Forçosamente, é também necessário dedicar a essas estatísticas um olhar interseccional. Veja bem, há outro elemento, por exemplo, boa parte dos dados da violência contra a população LGBTQIA+ é produzida pelo Grupo Gay da Bahia porque não existe produção governamental de relevância. Dados de violência contra travestis e transexuais são produzidos pela Associação Nacional de Travestis e Transexuais (Antra); dados sobre feminicídio são marcados por uma profunda subnotificação, esse é outro dilema para nós que estudamos violência de gênero e para aqueles que buscam combatê-la em termos de políticas públicas. Existe um viés de desqualificação de violência sofrida que passa pelo modo como essas violências são narradas, em muitas vezes, se não na maioria delas, existem estudos que comprovam essa realidade, a de que vão construir, seja para mulheres, seja para travestis e transsexuais, mas também para a população gay, não a condição de vítimas, mas a de culpados pela violência que sofreram.

Invariavelmente, os criminosos são protegidos. E nós vemos isso cotidianamente. Trata-se de algo muito grave que é observado nas pesquisas que tenho feito sobre violência de gênero. Essa invisibilização e desqualificação são flagrantes. Existe um fio que une esse processo de desqualificação ao processo de desqualificação enunciativa de nós mulheres na academia. Falando da academia, existe um fio que une a desqualificação das narrativas da população LGBTQIA+ que a atravessam, por isso sou entusiasta das epistemologias outras que podem vir a construir esse campo. Por exemplo, as 'epistemologias travestis', as 'epistemologias do escândalo', as 'epistemologias pajubeiras', todas elas têm muito a nos ensinar. Porque há um fio que atravessa essa violência e muitas vezes somos coniventes sem perceber. Parece-me urgente desvelar esse processo na pesquisa científica, e sei que existem muitas pessoas dedicadas a isso no nosso campo. É preciso promover também uma educação da própria mídia, não a mídia como abstração, mas com os profissionais, que eles possam ser preparados para não contribuir com essa subnotificação. Isso seria um

iii O Conselho Latino-Americano de Ciências Sociais (CLACSO) é uma instituição internacional não governamental com status associativo na Unesco, criada em 1967. Atualmente, reúne 736 centros de pesquisa e pós-graduação na área de ciências sociais e humanas em 51 países latino-americanos e de outros continentes. 
avanço impressionante. A violência é uma linguagem. A violência de gênero está ancorada em estratégias de silenciamento que são brutais.

Neste período de pandemia, nós fizemos no GT CLACSO Infancias y Juventudes uma análise comparativa para averiguar em que situação se encontrava a violência de gênero nos diferentes países da América Latina, Central e do Caribe representados em nosso grupo e o que encontramos foi o aumento de feminicídios, de violência doméstica, grande aumento da violência sexual contra meninas, em sua maioria, mas também contra meninos. Qual costuma ser o problema nesses casos? Muitas vezes, a total ausência de redes de apoio. Uma das coisas mais impactantes é o silenciamento, seja por agressão direta seja por desqualificação. Por exemplo, a criança que denuncia uma violência e escuta que aquilo não aconteceu ou que ela provocou aquela violência. É preciso analisar em que medida os governos em geral, e o nosso em particular, têm legitimado esse tipo de prática. Esses são alguns elementos bem marcantes, especificamente no estudo que faço no GT CLACSO. Só para voltar ao entretenimento, essa denúncia também aparece nas falas de artivistas como Jup do Bairro e Linn da Quebrada. Na aproximação com suas narrativas, vemos a violência, a precarização e a vulnerabilidade, mas vemos que dali emerge uma força de cura, de anamnese e de possível reparação.

Reciis: Artivismos musicais de gênero é um tema que atravessa seus estudos e sua fala. Poderia explicar um pouco sobre esse tema de pesquisa e no que ele derivou nos seus estudos recentes?

Rose de Melo Rocha: Artivismos musicais de gênero vão continuar no meu campo de investigação, fizeram parte do estudo que surgiu na Casa da Luz, no período da Revolta da Lâmpada, e ele acabou constituindo um campo de investigação de longo prazo. Esse estudo deu origem ao último livro que organizei pela Editora Devires, que é o Artivismos musicais de gênero: bandivas, trasvestis, gays, drags, trans, não-bináries (ROCHA, 2021). O conceito de artivismo, para o qual tento contribuir para uma melhor definição, implica em alguma ordem de ruptura com a arte e com a política, em suas dimensões canônicas. É um duplo enfrentamento, forçosamente constituído por esses dois elementos. Podemos pensar em três marcos históricos até chegar ao conceito de artivismo de gênero. Em um primeiro momento, nos anos 1970, ele emerge quando críticos de arte e alguns artistas se incomodam profundamente com a passividade da classe artística e dos críticos de arte diante do que vivia o país politicamente: ditadura, pós-golpe, torturas e repressões. A primeira convocação artivista parte desse lugar. $\mathrm{O}$ artivismo pode até partir de uma mobilização individual, mas ele deve chegar a uma dimensão pública e política. Ou seja, nem toda arte é ativista e nem todo ativismo é artístico. O segundo momento é acionado por experiências de ação política em rede e pela mobilização de elementos estéticos nessa ação, já em um marco da digitalização da cultura. Como terceiro momento nessa linha do tempo, os artivismos de gênero têm uma história, isso porque se volta a falar em artivismo no movimento das marchas juvenis, na esteira dos movimentos antiglobalização desencadeados no âmbito dos fóruns sociais globais. Há toda uma expressão ativista ética e política nas várias movimentações que atravessaram o país e o mundo. Por exemplo, no Ocupa São Paulo, mas passam também pelo Occupy Wall Street, pela Primavera Árabe. Esse universo e efervescência juvenil aliam arte e ativismo. Existe uma reenunciação do ativismo e da estética. Há um marco interessante no momento contemporâneo, uma reinterpretação dessa expressão ativismo/ativista nas marchas juvenis, isso especificamente no Brasil. Há um lugar importante desempenhado pela Marcha das Vadias, pois ela vai assumir claramente algo que entrelaça a vida pública urbana e a vida pública digital a partir de estratégias comunicacionais e estéticas de enfrentamento em relação tanto à estética quanto à política tradicionais. 
Leandro Colling (2018) apresenta algumas das condições de emergência do boom dos artivismos estéticos das dissidências de sexualidade e de gênero. Ele aponta outros elementos que mais recentemente vão constituir essas expressões. Isso se dá sempre em um trânsito de ações independentes que em algum momento se tornam convergentes, ou entram em diálogo. Figuras como Pabllo Vittar e Linn da Quebrada, para citar dois casos, são emblemáticas desta entrada protagônica e dissidente no universo mais amplo das visualidades, nas disputas audiovisuais. Há diferenças entre você participar de um programa de entrevistas, ser entrevistado pelo Faustão, e estar no seu próprio show em cena, com seu corpo. Isso é uma entrada, é uma disputa que passa pelo mainstream, mas vai para além dele. Porque jovens artivistas de gênero vêm acompanhando, são filhos dessa moderna cultura do Do It Yourself (DIY - Faça Você Mesmo). São filhos da digitalização da cultura. Isso foi um marco fundamental para nós pensarmos as reconfigurações que se dão no debate de gênero, algo que não podemos esquecer de apontar.

\section{Reciis: Como você analisa os movimentos feministas e LGBTQIA+ nas relações midiáticas? São lugares de reprodução de modos liberais ou (mas também) de espaço de visibilidade da resistência?}

Rose de Melo Rocha: Para responder sua perguntar vou citar (não literalmente) uma entrevista oferecida publicamente pela cantora Liniker, ao comentar sobre a série Manhãs de Setembro (Amazon) da qual participou e que estará em breve em circulação. Liniker foi questionada justamente sobre esse ingresso dos movimentos LGBTQIA+ no universo midiático e o que isso poderia promover. Concordo com a posição dela quando diz que é óbvio que há uma produção de esperança e de identificação, e que o fato de ela estar ali, enquanto uma presença audiovisual, que não está desqualificada, tem uma potencialidade. Mas ela problematiza se esta série, feita sobre uma existência travesti, não contasse - não é o caso da série - com uma atriz travesti e com pessoas trans e travestis em sua equipe como um todo. Ou seja, o set de filmagem precisa contar com uma representatividade de minorias, de dissidências sexuais e de gênero. Então, as mudanças têm que acontecer em vários planos. É interessante pensar em uma fala da antropóloga mexicana Maritza Urteaga (GARCÍA CANCLINI; CRUCES; URTEAGA, 2012): ela propõe que, assim como existem várias camadas de subalternização (e insisto em não falar em subalternidade), existem múltiplas camadas e possibilidades de resistências. Se eu não percebesse a centralidade da comunicação, como Jesus Martín-Barbero, como importante observatório do social, não estaria pesquisando o que pesquiso. E quero ler um trecho de uma fala da Rachel Virgínia, de As Baíasiv, quando ela vai comentar um videoclipe recente e diz: "Olhem bem essas imagens. Elas são fictícias sim. Mas ficção também molda realidades. Essas imagens. Felizes e amadas é a imagem que vamos projetar das travestis. Porque essa imagem que queremos ser. Livres, felizes e amadas. Por isso a música Primeiro Beijo e por isso um clipe leve onde somos correspondidas. Esse é nosso projeto de VIDA."

Essas falas ajudam bastante a pensarmos em como essas disputas por construir visibilidades outras podem contribuir para projetarmos nossas utopias realizáveis. Utopia tem sido uma palavra muito forte nos movimentos feministas e transfeministas dos quais participo. Não é por acaso. E por isso eu penso que pode existir esse campo de negociação com os espaços midiáticos.

iv As Baías é um trio musical brasileiro, formado na Universidade de São Paulo em 2011, onde a banda começou a se apresentar em festas universitárias. O grupo possui fortes influências de Gal Costa e do Clube da Esquina, e tem como mote na música identificar as formas de expressão das mulheres e das existências trans. 


\section{Reciis: Gostaria de voltara essa relação de mídia e política. Ainda atravessados pelos modos de vida na mídia, como esses movimentos se articulam com as instituições de Estado, garantindo seu direito de existir? Como você observa essa entrada/atravessamento do artivismo musical, da mídia e do entretenimento dentro das instituições de Estado?}

Rose de Melo Rocha: Estamos diante de uma luta entre uma política de morte e uma política de vida. Entre uma epistemologia do extermínio, uma gramática do extermínio e uma gramática da esperança. E nesse aspecto algumas das artivistas que estudo, algumas mais diretamente em suas letras, outras mais indiretamente, se referem a esse enfrentamento. Sobre tal enfrentamento é muito interessante observar como hoje se constroem redes aquilombadas de colaboração. Dessas redes aquilombadas podem participar pessoas como eu, uma irmã outsider (LORDE, 2019), como aliadas. Participam pessoas que estão na vida institucional, na política. Participam artistas. Participam ativistas. E gosto de lembrar nesse aspecto, sempre, a relação entre mídia e Estado. Em primeiro lugar, recordo uma declaração de Erica Malunguinho, a primeira mulher trans eleita deputada estadual em São Paulo, que dizia: "não queremos ser elogiadas por resistir, queremos existir". Penso que nesse entrelaçar entre a mídia, os artivismos e as instituições de Estado, o embate é esse: ir além do discurso da resistência, não que ele não seja importante, mas ir além e construir uma perspectiva do direito a existir.

Como propõe a pesquisadora colombiana Alma Anomalia, madre de uma casa vogue parceira do grupo de pesquisa Juvenália ${ }^{v}$, dissidências sexuais e de gênero já são muito visíveis, já provocam muito com a sua visibilidade. Hoje, diz Alma, elas lutam pelo direito à presença nas cidades, nas manifestações, nas instâncias políticas, mas também por empregabilidade, por inserção educacional etc. Vocês estão acompanhando o que está acontecendo na Colômbia, com o Paro Nacional, e ela e o grupo da House of Anomalía estão em campo. Elas relatam um momento em que chegam em uma manifestação, estão de saia, com várias de suas escolhas estéticas, e um homem se aproxima e diz a elas que a manifestação não era de veado ou de sapatão. Não era manifestação de travestis. Você percebe como a luta estético-política é intrincada. Existem questões muito sérias. Isso atravessa o debate institucional. Portanto, digo que é importante a ocupação do espaço midiático, mas isso não basta, porque há questões muito sérias referentes, por exemplo, ao modo pelo qual as travestis são incluídas nas dinâmicas sociais. Uma Reis Sorrequia, pesquisadora do Juvenália, mestranda no Programa de Pós-Graduação Stricto Sensu em Comunicação e Práticas de Consumo da ESPM (PPGCOM-ESPM), travesti, aponta a inclusão forçada das travestis no mercado do sexo. Não há aqui um julgamento moral, mas a denúncia de um cerceamento social e existencial. Lohana Berkins (2017), citada por Uma Sorrequia, se refere à ideia de as travestis viverem encurraladas pelo sexo. É um projeto de inclusão estigmatizante. A alteração dessa perspectiva, forçosamente, precisa atravessar várias instâncias de representatividade e construção de legibilidade pública. Em termos institucionais, o fato de termos mandatos e mandatas coletivos voltados às várias possibilidades de identidades sexuais e de gênero significa um avanço histórico importante, relacionado com experiências de horizontalidade que foram exercidas nas marchas juvenis. As lideranças estudantis, universitária e secundarista já tinham forte perfil ativista. Considero isso um avanço histórico importantíssimo, e que tenham ascendido a mandatos políticos, mais ainda. Isso não quer dizer que não estejam sendo perseguidas. Mas estão lutando. É um avanço histórico.

Penso também na relação mídia e Estado, considerando a subnotificação de casos de violência de gênero da qual já falamos, que caracteriza a violência de gênero no Brasil e em toda a América Latina. Muitas vezes, os registros noticiosos são os únicos disponíveis para quantificar e qualificar esses casos de violência.

v O grupo de pesquisa, constituído em março de 2015, tem caráter interinstitucional e transdisciplinar, tendo em sua agenda de discussões temas, pesquisas e autores de ponta nacionais e internacionais, com ênfase nas áreas da comunicação, dos ativismos, da política, da estética, do entretenimento e do consumo. 
Mas invariavelmente não os qualifica. Nesse sentido, insisto em uma ideia de educação dos meios e também da polícia. Isso porque os boletins de ocorrência também são fontes para a produção de informação sobre essa violência e os modos como os crimes são narrados - o que já havia percebido quando estudei no doutorado sobre estética da violência - também constroem uma história de invisibilização e silenciamento.

Vivemos uma guerra, uma disputa constante entre a necropolítica e o que o José Manuel Valenzuela Arce (2014) chama de resistências juvenis biopolíticas, para não reforçar apenas o que há de destruição. Temos que reforçar o que está sendo construído. Existem também inúmeras resistências biopolíticas das quais os artivismos musicais de gênero fazem parte. Não caminham sós, mas precisam e devem se articular a políticas públicas. É óbvio que há instâncias e instâncias. A nós cabe levar essa reflexão profundamente para a academia como pesquisadoras e pesquisadores.

Reciis: Como analisa os feminismos contemporâneos e suas pautas de reivindicações nas dinâmicas históricas? Há permanências, rupturas, avanços e desafios?

Rose de Melo Rocha: Vejo com otimismo, mas também com alguns pontos de preocupação que permanecem. Quando comecei a militar no movimento, no final dos anos 1980, eu participava de um grupo partidário que estava articulado ao que chamávamos de Movimento de Mulheres. Isso sinaliza uma série de coisas. Quando olho hoje para o meu espaço de militância e de reflexão intelectual, tenho muita satisfação de me ver fazendo parte de um feminismo que não rechaça o transfeminismo, por exemplo, muito ao contrário. Na verdade, não concebo um feminismo que não seja transfeminista, com toda a reflexão sobre o lugar que ocupo, como me alio e como sou percebida como aliada. E, no meu caso, acredito na perspectiva de um feminismo que partilha da ideia de se constituir uma rede aquilombada. Essa é a minha perspectiva, um feminismo que almeja a equidade e não o essencialismo identitário, embora reconheça claramente a importância estratégica das lutas identitárias como apresentado por autores como Paco Vidarte (2019) sobre a "ética bixa". Mas me parece interessante a perspectiva apresentada pelo José Estebán Muñoz (1999), cubano, radicado nos Estados Unidos, falecido há alguns anos, com seu conceito de desindentificação como performance política. Estebán Muñoz (1999) apresenta uma pequena guinada em relação a Butler. Ele apresenta a questão de negociarmos identidades, seja para negá-las, seja para tomá-las em uma forma estratégica, inclusive negociando com a cultura dominante, mas construindo uma performance outra. Lembra muito a proposta de atuação da Linn da Quebrada, que trouxe a ideia de 'enviadescer'. 'Enviadescer' como um convite para todes, para todas e todos. Acredito nessa perspectiva inclusiva e acho que esse é um desafio para os feminismos, uma luta contra os essencialismos e contra as opressões de gênero. Sou alguém que aprendeu muito com o transfeminismo. Outro desafio ainda presente para os movimentos feministas, foi uma virada para mim e para a minha formação, é o debate da interseccionalidade, vendo as feministas negras, pensando em Angela Davis (2016) e Patrícia Hill Collins (2019), mas também pensando nas autoras do Brasil, como Lélia Gonzalez (2020) e Conceição Evaristo (2017). A interseccionalidade tem que ser percebida em sentido amplo, no que diz respeito às questões sociais, étnicas, de gênero, mas também de classe e de transgeneridade. Entendo que é um avanço e um desafio ao mesmo tempo. Penso como um dos maiores desafios hoje, considerando os embates fortíssimos nas existências vinculadas ao debate de gênero. Vivemos um debate muito forte entre políticas identitárias e pós-identitárias, mas percebo como desafio essa ideia de podermos amalgamar as lutas. Donna Haraway (2019) diz que temos por desafio construir novas parentalidades, inclusive com os estranhos. É o desafio que envolve os movimentos feministas e de gênero e a todos e todas aqueles que buscam um mundo outro de equidade, de amor, como fala bell hooks (2021), ou da epistemologia da esperança de Florencia Saintout (2015). Como dizia Laclau (2011), devemos tornar a política novamente pensável. 
Esse é o desafio para todas, todes e todos nós, entendendo que as lutas antipatriarcais contemplam e ultrapassam os feminismos e envolvem outros grupos. Nesse sentido, dedico uma atenção especial às políticas queer na América Latina, talvez elas indiquem outra agenda social de mudanças, um outro comum possível. Por isso, de novo, a importância das ações estéticas, os enfrentamentos que vivemos hoje e não vivíamos em outros momentos. Nesse exato momento, vivemos enfrentamentos a regimes que não são apenas fascistas, são alucinatórios. Eles tentam reverter toda luta emancipatória em desvios, balelas, mimimi. E me impressiona a reprodução desses discursos no cotidiano, de um modo desavisado. Percebo que os feminismos hoje devem encampar os movimentos de reparação do povo negro, do povo indígena, das minorias, das dissidências sexuais e de gênero. Participar ativamente da consolidação de novas epistemes. Aqui se unem a militância e o trabalho científico. Também vejo como uma força que pode aquilombar e amalgamar com outras. Assim, nessa direção, percebo com muito otimismo o fato de os feminismos terem encampado também aquilo que Audre Lorde (2019) chama de salto desejante, que aponta para a potência do desejo das mulheres, a potentia gaudendi de Paul B. Preciado (2018). E eu acredito nessa potência erótica como uma nova episteme. Eu não acredito sozinha, tem muita gente trabalhando nessa direção.

Vou citar dois grupos aos quais ainda não fiz referência direta, mas que trabalham com essas propostas: 0 grupo de pesquisa Juvenália, que lidero, e que está presente como eco nas minhas falas. Trabalhamos desde 2015 com as questões de gênero, com o debate identitário e pós-identitário, com a interseccionalidade. O outro, é o núcleo de investigação Nusur - descolonizando o pensamento e a arte, que é um núcleo de investigação e estudos pós-coloniais, de performance, identidade, diáspora e feminismo para promover conhecimentos situados e compartilhados. São dois espaços importantes e que apontam para essa luta. Os estudos de gênero são fundamentais para que nós possamos descolonizar o pensamento e a arte, e por isso me encantam os artivismos musicais de gênero.

\section{REFERÊNCIAS}

BAITELLO, Norval. A era da iconofagia. São Paulo: Paulus, 2014.

BERKINS, Lohana. Anatomía política del cuerpo travesti. Lavaca, Buenos Aires, 31 dez. 2007. Disponível em: https://lavaca.org/mu11/anatomia-politica-del-cuerpo-travesti/. Acesso em: 29 jun. 2021.

BORELLI, Silvia Helena Simões; ROCHA, Rose de Melo; OLIVEIRA, Rita de Cássia Alves (coord.). Jovens na cena metropolitana: percepções, narrativas e modos de comunicação. São Paulo: Paulinas, 2009.

BORGES, Jorge Luis. Ficções. Rio de Janeiro: Companhia das Letras, 2007.

BUTLER, Judith. Problemas de gênero: feminismo e subversão da identidade. Rio de Janeiro: Civilização Brasileira, 2003.

COLLING, Leandro. A emergência dos artivismos das dissidências sexuais e de gêneros no Brasil da atualidade. Sala Preta, São Paulo, v. 18, n. 1, p. 152-167, 2018. DOI: https://doi.org/10.11606/issn.22383867.v18i1p152-167. Disponível em: https://www.revistas.usp.br/salapreta/article/view/125684. Acesso em: 29 jun. 2021.

COLLINS, Patrícia Hill. Pensamento feminista negro: conhecimento, consciência e a política do empoderamento. São Paulo: Boitempo, 2019.

DAVIS, Angela. Mulheres, raça e classe. São Paulo: Boitempo, 2016.

ESTEBÁN MUÑOZ, José. Disidentifications: queers of color and the performance of politics. Mineápolis: University of Minnesota Press, 1999.

EVARISTO, Conceição. Becos da memória. Rio de Janeiro: Pallas, 2017.

FREIRE, Paulo. Pedagogia do oprimido. Rio de Janeiro: Paz e Terra, 1998. 
GARCÍA CANCLINI, Néstor; CRUCES, Francisco; URTEAGA, Maritza (coord.). Jóvenes, culturas urbanas y redes digitales: prácticas emergentes en las artes, las editoriales y la música. Madri: Fundación Telefonia, 2012.

GONZALEZ, Lélia. Por um feminismo afro-latino-americano. Rio de Janeiro: Zahar, 2020.

HALL, Stuart. Identidade cultural na pós-modernidade. Rio de Janeiro: DP\&A, 2004.

HARAWAY, Donna. Seguir con el problema: generar parentesco en el Chthuluceno. Rio de Janeiro: Consonni, 2019.

HOOKS, Bell. Tudo sobre o amor. São Paulo: Elefante, 2021.

KAPLAN, Ann. O mal-estar no pós-modernismo. Rio de Janeiro: Jorge Zahar Editora, 1993.

LACLAU, Ernesto. Emancipação e diferença. Rio de Janeiro: EdUERJ, 2011.

LORDE, Audre. Irmã outsider: ensaios e conferências. Belo Horizonte: Autêntica, 2019.

MARTÍN-BARBERO, Jesús. De los medios a las mediaciones: comunicación, cultura y hegemonía. Barcelona: Anthropos, 2010.

MARTÍN-BARBERO, Jesús. Ofício de cartógrafo: travessias latino-americanas da comunicação na cultura. São Paulo: Loyola, 2004.

PRECIADO, Paul B. Testo junkie: sexo, drogas e biopolítica na era farmacopornográfica. São Paulo: n-1 edições, 2018.

RINCÓN, Omar. Lo popular en la comunicación: culturas bastardas + ciudadanías celebrities. In: AMADO, Adriana; RINCÓN, Omar (ed.) La comunicación en mutación: remix de discursos. Bogotá: FES Comunicación, 2015. p. 23-42.

ROCHA, Rose de Melo. A vertigem do olhar: manifestações graffitadas e transformações na comunicação, no espaço e no tempo urbanos. 1992. 256 f. Dissertação (Mestrado em Comunicação Social). - Instituto Metodista de Ensino Superior, São Bernardo do Campo, 1992.

ROCHA, Rose de Melo. Imaginários do excesso e sedução do artifício: hipermulheres e seus paraísos infernais. In: D’ABREU, Patrícia Cardoso; RIBEIRO, Ana Paula Goulart. (org.). Mulher, cultura e mídia: investigações sobre o feminino. Rio de Janeiro: Multifoco, 2018. p. 31-58.

ROCHA, Rose de Melo. Estética da violência: por uma arqueologia dos vestígios. 1997. 284 f. Tese (Doutorado em Ciências da Comunicação). - Universidade de São Paulo, São Paulo, 1998.

ROCHA. Rose de Melo. Artivismos musicais de gênero: bandivas, travestis, gays, drags, trans, nãobináries. Salvador: Devires, 2021.

SAINTOUT, Florencia; VARELA, Andrea. Voces abiertas: comunicación, política y ciudadanía en América Latina. La Plata: Universidad Nacional de La Plata; Buenos Aires: CLACSO, 2015.

VALENZUELAARCE, José Manuel. El futuro ya fue: socioantropología de I@s jóvenes en la modernidad. Tijuana: El Colegio de la Frontera Norte, 2014.

VIDARTE, Paco. Ética bixa: proclamações libertárias para uma militância LGBTQ. São Paulo: n-1 Edições, 2019. 